\title{
Affirmative Action Exemptions and Capacity Constrained Firms Online Appendix
}

\author{
Justin Marion
}

\section{A Two period model}

Here I present a simplified version of the model with an analytical solution. I assume that the game lasts only two periods, procurement contracts are allocated using a sealed bid secondprice auction and each bidder's per-task cost is independent and uniformly distributed over the unit interval. The latter, along with the assumption $c_{h} \geq 1$, ensures that affirmative action will be binding in period two.

One project is awarded per period. In period one, each firm receives its cost draw for that period's project, and chooses a bid $b_{i, 1}$ and subcontracting level $h_{i, 1}$. The firm submitting the lowest bid wins and receives as payment the bid of the second lowest bidder. The winner from period 1 is exempt from affirmative action in period 2 if $h_{i, 1} \geq \bar{p}$. ${ }^{1}$ Otherwise, neither firm is exempt. In period 2, each firm learns its cost $c_{i 2}$ for the period 2 project, chooses a bidding and subcontracting strategy subject to the affirmative action constraint, and a new auction is conducted. Then the game ends.

\section{Period 2:}

The model can be solved by backward induction. Period 2 is the end of the game, so firms will select the minimum level of subcontracting allowed. Since it is not possible in the model for both firms to be eligible in the same time period, there are two relevant cases to analyze. Case 1: neither $i$ nor $j$ are exemption eligible. Case 2: one firm is eligible, the other is not. The total cost of an ineligible firm is $C_{i}=\left(1-g_{2}\right) c_{i}+g_{2}\left(c_{2 h}+\gamma H_{t-1}\right)$, distributed $U[\underline{C}(H), \bar{C}(H)]$, where $\underline{C}(H)=g_{2}\left(c_{h 2}+\gamma H_{1}\right)$ and $\bar{C}(H)=1-g_{2}+g_{2}\left(c_{h 2}+\gamma H_{1}\right){ }^{2}$ An

\footnotetext{
${ }^{1}$ In the full model, exemption eligibility was determined by several periods of subcontracting choices. Note that with only two periods, the points determining firm $i$ 's exemption eligibility are simply given by $p_{i}=h_{i 1} I\left(b_{i}<b_{-i}\right.$, the amount of period 1 DBE subcontracting selected if $i$ wins.

${ }^{2}$ I will mostly refer to the boundaries of the cost distribution as $\underline{C}$ and $\bar{C}$, dropping the reference to their dependence on $H$. The term $H_{1}$ will depend on the subcontracting choices made by the winner in period 1.
} 
eligible bidder's cost is simply $C_{i}=c_{i}$, distributed $U[0,1]$. The dominant period 2 strategy is to submit a bid equal to total cost. ${ }^{3}$

Case 1: Here the two firms are symmetric. The ex ante expected profit for each firm is

$$
E \Pi_{\text {case } 1}=\left(1-g_{2}\right) / 6
$$

This will represent the continuation value of winning the period 1 auction when using a subcontracting level that does not qualify the firm for an exemption, as well as the continuation value of losing when the firm's opponent in period 1 sets a non-qualifying subcontracting level.

The expected winning bid is the expected second highest cost:

$$
E\left[C_{\{2\}}\right]=\underline{C}+\frac{2}{3}(\bar{C}-\underline{C})
$$

while the expected cost of the winning bidder is

$$
E\left[C_{\{1\}}\right]=\underline{C}+\frac{1}{3}(\bar{C}-\underline{C})
$$

Note that equations (1)-(3) highlight one overlooked aspect of affirmative action. More intensive affirmative action shrinks the cost distribution, which reduces information rents and mitigates the cost of affirmative action to the government.

Case 2: Here, one firm is eligible while the other is not, leading to a cost asymmetry. If $i$ is eligible, the expected profits of the eligible and ineligible firms are respectively given by

$$
E \Pi_{i, c a s e 2}=\frac{\bar{C}(\bar{C}-1)+\left(1-\underline{C}^{3}\right) / 3}{2\left(1-g_{2}\right)}
$$

and

$$
E \Pi_{-i, \text { case } 2}=\frac{\underline{C}(\underline{C}-1)+\left(1-\underline{C}^{3}\right) / 3}{2\left(1-g_{2}\right)}
$$

where $\underline{C}$ and $\bar{C}$ refer to the lower and upper bounds of the ineligible firm's cost distribution. The eligible firm enjoys higher profits, since the first term in the numerator is positive for firm $i$ and negative for $-i$. The average winning bid is

$$
E\left[C_{\{2\}}\right]=\frac{\bar{C}+\underline{C}}{2}-\frac{(\underline{C}-1)^{3}}{6\left(1-g_{2}\right)}
$$

\footnotetext{
${ }^{3}$ When one firm is eligible, eg firm $i$, it is possible that $C_{-i}>1$, I assume that in those cases firm $-i$ also bids its cost even though the probability of winning is zero.
} 
and the expected cost of the winning bidder is

$$
E\left[C_{\{1\}}\right]=\frac{1}{2}+\frac{(\underline{C}-1)^{3}}{6\left(1-g_{2}\right)} .
$$

The first term of this expression is the average cost of the eligible firm. The average cost of the winning firm is lower than this since the winning cost is the minimum of the eligible and ineligible firms.

\section{Period 1:}

Having established the payoffs for each outcome in period 2, we can characterize firm $i$ 's objective function

$$
V=\left[E\left[b_{-i} \mid b_{i}<b_{-i}\right]-C_{i}\left(h_{i}\right)+V\left(h_{i}, 0\right)\right] \operatorname{Pr}\left(b_{i}<b_{-i}\right)+\left(1-\operatorname{Pr}\left(b<b_{-i}\right)\right) E\left[V\left(0, h_{-i}\right)\right]
$$

where the discount rate is set at $\delta=1$. As in Jeziorski and Krasnokutskaya (2013), the level of subcontracting does not effect the probability of winning or the continuation value of losing. Therefore, substituting for $C_{i}(),. h_{i}$ is chosen to maximize $-\left(1-h_{i}\right) c_{i}-h_{i} c_{h 1}+V\left(h_{i}, 0\right)$. Notice that this is independent of the subcontracting choice of $-i$.

The key strategic decision in setting $h$ involves raising rival's costs. An eligible firm increasing $h$ today increases its rival's costs in the future but not its own. Therefore an incentive exists to subcontract more than is required to gain eligibility $\left(h_{i}>\bar{p}\right)$.

The objective function is not concave in $h_{i}$ and an interior solution does not obtain. The optimal level of subcontracting will take on one of three values: $h_{i} \in\left\{g_{1}, \bar{p}, \bar{h}\right\}$, determined by the contractors' per-task cost $c_{i}$ relative to thresholds $\widetilde{c}_{g}$ and $\widetilde{c}_{p}$. Lower cost firms choose lower levels of subcontracting. The thresholds are derived by comparing the objective function at $h=\bar{p}, h=g_{1}$, and $h=\bar{h}$ and are given by

$$
\widetilde{c}_{g}=c_{h 1}-\frac{V(\bar{p}, 0)-V\left(g_{1}, 0\right)}{\bar{p}-g_{1}}
$$

and

$$
\widetilde{c}_{p}=c_{h 1}-\frac{V(\bar{h}, 0)-V(\bar{p}, 0)}{\bar{h}-\bar{p}} .
$$

This highlights two determinants of the subcontracting decision. First, when the firm's current own per-task cost is high relative to that of the subcontractor, meeting or exceeding the level of utilization needed for eligibility is more attractive. Second, the expected future value of being exemption eligible leads to a dynamic incentive for subcontracting. The difference $V(\bar{p}, 0)-V\left(g_{1}, 0\right)$ is driven by both the value of having lower future cost and from raising the cost of the rival, while $V(\bar{h}, 0)-V(\bar{p}, 0)$ is driven by the latter. 
The dominant bidding strategy involves submitting a bid equal to the firm's total period 1 cost less the difference in continuation value between winning and losing:

$$
b\left(c_{i}\right)=C_{i}\left(h_{i}^{*}\left(c_{i}\right)\right)-\left(V\left(h_{i}^{*}\left(c_{i}\right), 0\right)-E\left[V\left(0, h_{-i}\right)\right]\right) .
$$

The intuition is as follows. Suppose the firm bid its construction cost. It would then be possible to lose to a competitor bidding $C_{i}-\epsilon$, though winning any auction where $b_{-i} \geq$ $C_{i}-\left(V\left(h_{i}^{*}(c), 0\right)-E\left[V\left(0, h_{-i}\right)\right]\right)$ would increase the present value of profits.

The expected continuation value of losing, $E\left[V\left(0, h_{-i}\right)\right]$, depends on the set of costs to which the firm loses. This is because $h_{-i}$ depends on $c_{-i}$. In a symmetric equilibrium firm $i$ will only lose to $-i$ if $c_{i}>c_{-i}$. Therefore,

$$
E\left[V\left(0, h_{-i}\right)\right]= \begin{cases}V\left(0, g_{1}\right) & \text { if } c<\widetilde{c}_{g} \\ \frac{\widetilde{c}_{g}}{c_{i}} V\left(0, g_{1}\right)+\frac{c_{i}-\widetilde{c_{g}}}{c_{i}} V(0, \bar{p}) & \text { if } \widetilde{c}_{g}<c<\widetilde{c}_{p} \\ \frac{\widetilde{c_{g}}}{c_{i}} V\left(0, g_{1}\right)+\frac{\widetilde{c_{p}}-\widetilde{c}_{g}}{c_{i}} V(0, \bar{p})+\frac{c_{i}-\widetilde{c}_{p}}{c_{i}} V(0, \bar{h}) & \text { if } c>\widetilde{c}_{p}\end{cases}
$$

where $V\left(0, g_{1}\right), V(0, \bar{p})$, and $V(0, \bar{h})$ are as calculated in equations $(1)$ and $(5)$.

The bid function described in equation (11) is monotonic in $c_{i}$. Consequently, the lowest cost firm wins and receives payment equal to the bid of the highest cost firm. The distribution of the winning and losing costs are $F_{\{1\}}(c)=1-(1-F(c))^{2}$ and $F_{\{2\}}(c)=F(c)^{2}$. The expected period one winning bid is therefore $\int_{0}^{1} b(c) f_{\{2\}}(c) d c$ and expected winning cost $\int_{0}^{1} c f_{\{1\}}(c) d c$.

Equations (11) and (12) reveal that the continuation value of winning is highest for highcost firms, and the continuation value of losing is lowest. The exemption program therefore will have the largest effect on the bids of high-cost firms and will thereby lower the expected winning bid.

This effect is illustrated in Figure 1, where I have plotted the optimal bid against the prime contractor's per-task cost $c_{i}$. With a second-price auction and no affirmative action, $b_{i}=c_{i}$. With affirmative action, the firm's total cost is increased to $C=(1-g) c_{i}+g c_{h}$ and bids are correspondingly higher. The exemption program has no effect on the bid function of the lowest cost firms, since the low cost firms do not seek exemption eligibility, making the continuation values of winning and losing identical. However, the exemption program leads to a lower bid for firms where $c_{i}>\widetilde{c}_{g}$, since winning an auction would mean being exempt next period while losing might result in facing an exempt firm in the next period. 
Figure 1: Bid as function of firm's own per-task cost

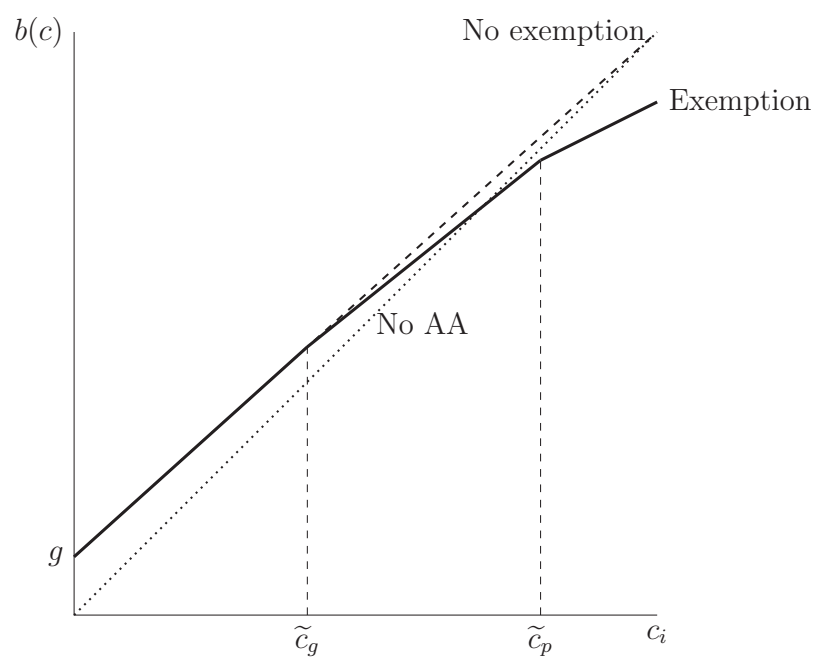

\section{A.1 Subcontracting comparative statics}

Consider the response of period 1 subcontracting to parameters affecting period 2 cost: $c_{h 2}$, $\gamma$, and $g_{2}$. The expected value of period one DBE subcontracting across bidders is

$$
\begin{aligned}
E\left[h_{i 1}\right] & =\widetilde{c}_{g} g_{1}+\left(\widetilde{c}_{p}-\widetilde{c}_{g}\right) \bar{p}+\left(1-\widetilde{c}_{p}\right) \bar{h} \\
& =\bar{h}-\widetilde{c}_{g}\left(\bar{p}-g_{1}\right)-\widetilde{c}_{p}(\bar{h}-\bar{p})
\end{aligned}
$$

If we consider some parameter $\zeta$, then the derivative of $E\left[h_{i 1}\right]$ with respect to $\zeta$ reduces to $\frac{\partial E\left[h_{i 1}\right]}{\partial \zeta}=\frac{\partial V(\bar{h}, 0)}{\partial \zeta}-\frac{\partial V\left(g_{1}, 0\right)}{\partial \zeta}$. Applying this expression to each of the parameters of interest, we see the following:

$$
\begin{gathered}
\frac{\partial E\left[h_{i 1}\right]}{\partial \gamma}=\frac{\bar{h} g_{2}\left(2 \bar{C}(\bar{h})-1-\underline{C}(\bar{h})^{2}\right)}{2\left(1-g_{2}\right)}>0 . \\
\frac{\partial E\left[h_{i 1}\right]}{\partial c_{h 2}}=\frac{g_{2}\left(2 \bar{C}(\bar{h})-1-\underline{C}(\bar{h})^{2}\right)}{2\left(1-g_{2}\right)}>0 .
\end{gathered}
$$

Neither $\gamma$ nor $c_{h 2}$ affect the continuation value of winning when ineligible, so their effect works entirely through $V(\bar{h}, 0)$. Both have a positive impact on the continuation value of winning, as they increase the cost advantage of period two eligibility.

$$
\frac{\partial E\left[h_{i 1}\right]}{\partial g_{2}}=\frac{\partial V(\bar{h}, 0)}{\partial g_{2}}+\frac{1}{6}>0 .
$$

Increasing next period's goal increases the continuation value of over-complying, since it raises rival's cost in the next period, and decreases the continuation value of exactly complying since this is decreasing in the anticipated affirmative action goal. 


\section{A.2 Parameterized model}

I now parameterize the model with and without an exemption program. In this parametrization, I vary the values of $c_{h 2}$, while fixing the values of the other parameter values: $\gamma=1$, $c_{h 1}=1, \bar{p}=0.05, g_{1}=0.025$, and $g_{2}=0.05$.

The results are shown in Table 1 . In column 1, I show the benchmark case without affirmative action. In the following columns, I show the winning bid, winning cost, and level of subcontracting with and without an exemption program under two scenarios for the period 2 cost of the subcontractor, one where it does not change and the other where it is anticipated to go up by 20 percent.

Table 1: Parameterization exercise

\begin{tabular}{|c|c|c|c|c|c|}
\hline & \multirow[b]{2}{*}{ No AA Benchmark } & \multicolumn{2}{|c|}{$c_{h 1}=c_{h 2}=1$} & \multicolumn{2}{|c|}{$c_{h 1}=1, c_{h 2}=1.2$} \\
\hline & & No exemption & Exemption & No exemption & Exemption \\
\hline $\mathrm{E}[$ Construction cost $]$ & 0.67 & 0.7179 & 0.7153 & 0.7279 & 0.7219 \\
\hline E[Winning Bids] & 1.333 & 1.360 & 1.340 & 1.370 & 1.330 \\
\hline E[Subcontracting] & & 0.075 & 0.075 & 0.075 & 0.074 \\
\hline Extra cost per sub. & & 0.683 & 0.652 & 0.817 & 0.750 \\
\hline Extra bid per sub. & & 0.350 & 0.088 & 0.483 & -0.043 \\
\hline$\widetilde{c}_{q}$ & & & 0.264 & & 0.051 \\
\hline$\widetilde{c}_{p}$ & & & 0.973 & & 0.973 \\
\hline
\end{tabular}

This table shows the results of parameterizing the model under several scenarios. The first column shows the expected outcomes in a benchmark scenario of no affirmative action. The construction cost, winning bid, and subcontracting figures are the sum of their expected values across the two periods. The extra cost and extra bid per subcontracted task are the difference in cost from the no affirmative action benchmark divided by the number of tasks awarded to subcontractors. The eligibility threshold for the exemption program is $\bar{p}=0.05$. In all cases, $\gamma=1$ and $\bar{h}=0.5$.

The degree of subcontracting without exemptions is by definition equal to the affirmative action goal. The exemption program leads to a virtually identical level of subcontracting. The cost thresholds $\widetilde{c}_{g}$ and $\widetilde{c}_{p}$ illustrate how the model parameters affect the dynamic subcontracting incentives. Increasing the period two DBE cost reduces $\widetilde{c}_{g}$ noticeably, leading to a greater range of firms wanting to subcontract in excess of the affirmative action requirement to gain future exemption eligibility.

Affirmative action is more efficient under the exemption program, and the effect is greatest when DBE subcontractor costs are expected to increase. The exemption program improves the cost per subcontracted task by 8.2 percent when DBE costs increase in period 2 compared to 4.5 percent when DBE costs are stable.

The effect of the exemption program on government expenditures is disproportionate to the construction cost effect. The sum of the expected winning bid across the two periods is substantially lower under the exemption program. Furthermore, when DBE costs are 
expected to rise, and consequently the continuation value of winning is high, the procurement cost is actually lower under the exemption program than under the no affirmative action benchmark. In other words, affirmative action along with exemptions lowers government expenditures in this scenario. 


\section{B Further evidence for contract volume}


Table 2: Interactions with Past and Future DBE Demand



Standard errors are in parentheses. $* * *, * * *$ denote significance at the $10 \%, 5 \%$, and $1 \%$ level, respectively.

The unit of observation is a bidder in an auction. Contracts with a DBE goal of zero are excluded.

As indicated by the column titles, the dependent variables are either the ratio of the percentage DBE commitment to the project goal or an indicator for meeting at least 80 percent of the project goal. Each specification includes contractor fixed effects. The top 5 percent of the commitment-goal ratio is topcoded.

Other covariates are contractor effects, an indicator for the goal being 5 percent, and letting year and month effects.

The specifications in Columns (1) and (2) only include auctions conducted in 2011 and 2012, where points are observed for both eligible and ineligible bidders. 


\section{Proposal guaranty}


Table 3: Estimated cost and proposal guaranty, 2013

\begin{tabular}{|c|c|}
\hline Estimated size & Proposal guaranty \\
\hline$<\$ 5,000$ & 250 \\
\hline $5,000-10,000$ & 500 \\
\hline $10,000-20,000$ & 1,000 \\
\hline $20,000-40,000$ & 2,000 \\
\hline $40,000-80,000$ & 4,000 \\
\hline $80,000-125,000$ & 6,250 \\
\hline $125,000-250,000$ & 12,500 \\
\hline $250,000-500,000$ & 25,000 \\
\hline $500,000-750,000$ & 37,500 \\
\hline $750,000-1,000,000$ & 50,000 \\
\hline $1,000,000-1,250,000$ & 62,500 \\
\hline $1,250,000-1,500,000$ & 75,000 \\
\hline $1,500,000-2,000,000$ & 100,000 \\
\hline $2,000,000-2,500,000$ & 125,000 \\
\hline $2,500,000-3,000,000$ & 150,000 \\
\hline $3,000,000-3,500,000$ & 175,000 \\
\hline $3,500,000-4,000,000$ & 200,000 \\
\hline $4,000,000-5,000,000$ & 250,000 \\
\hline $5,000,000-7,500,000$ & 375,000 \\
\hline $7,500,000-10,000,000$ & 500,000 \\
\hline $10,000,000-15,000,000$ & 750,000 \\
\hline $15,000,000-20,000,000$ & $1,000,000$ \\
\hline $20,000,000-25,000,000$ & $1,250,000$ \\
\hline $25,000,000-30,000,000$ & $1,500,000$ \\
\hline
\end{tabular}


Figure 2: Relationship between log bid and log proposal guaranty

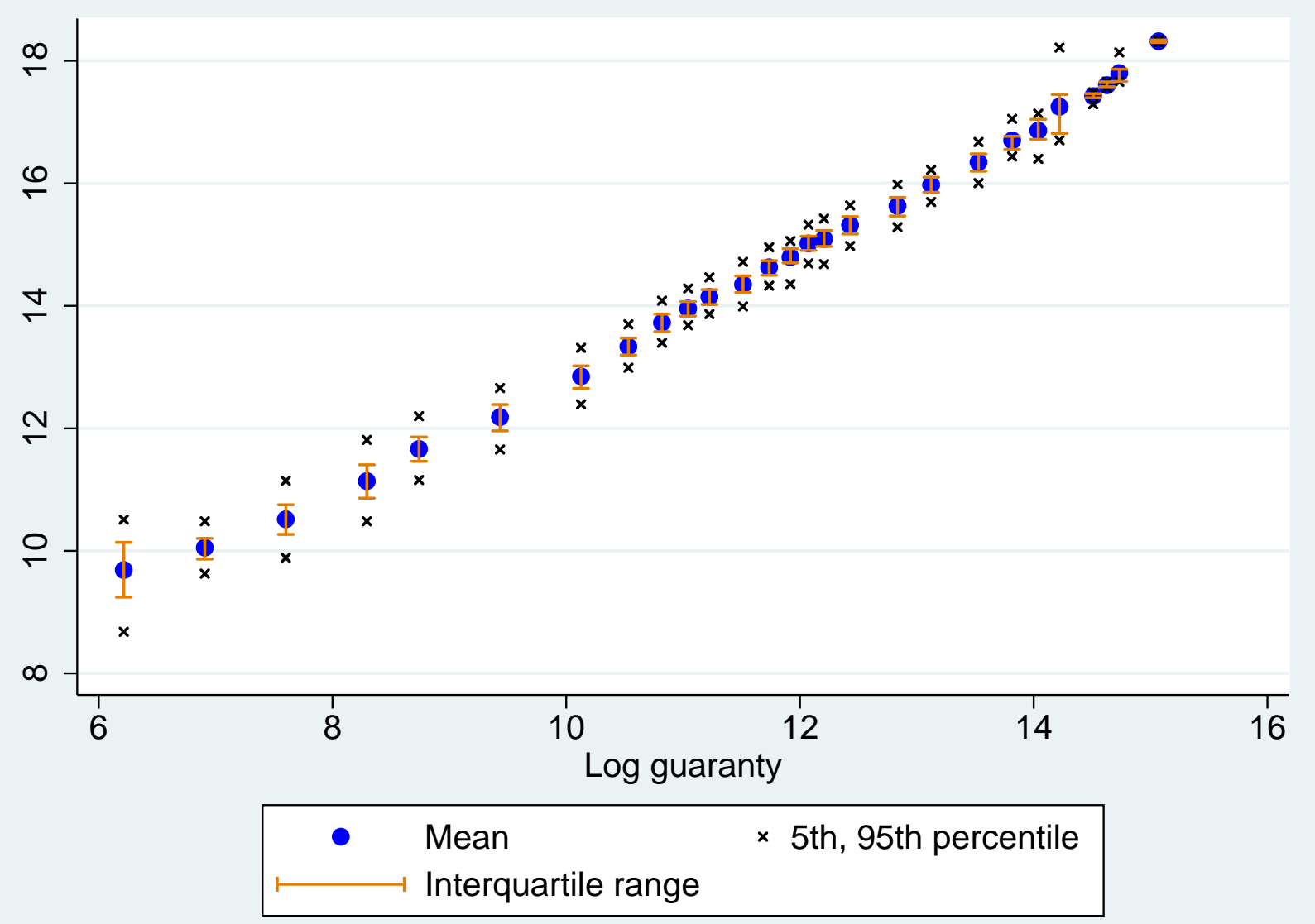




\section{References}

Jeziorski, Przemyslaw, and Elena Krasnokutskaya. 2013. "Dynamic Auction Environment with Subcontracting." 